\title{
B046 AN AEM SURVEY OF A LEAKING LANDFILL
}

\begin{abstract}
This study presents results obtained from a remarkably small-scale helicopter airborne electromagnetic (AEM) survey of a closed landfill. The landfill, occupying a former quarry, is situated among shallow, worked-out coal seams (pillar and stall workings) and was located over at least two mineshafts that occupied the quarry floor. The landfill was known to be leaking from an extensive borehole investigation that took place in the 1970's, when the landfill was active. Redevelopment issues and associated, proposed surface extraction of coals have renewed interest in the possible pollution threat of waste products. Of particular concern is the extent to which pollution has, potentially, transgressed a fault to the north and entered the area of proposed regeneration. The airborne survey data (EM and magnetic) were obtained using the six-frequency RESOLVE bird using a flight line spacing of $40 \mathrm{~m}$. The data acquired have been subjected to $1 \mathrm{D}$ regularized inversion to enable a 3D conductivity model to be assessed. The model clearly identifies the landfill as a source term of highly conductive materials. At conductivities that are a factor of 3 above background, evidence for a variety of vertically compact, lateral migration pathways, largely below the base of the quarry, is obtained.
\end{abstract}

\section{The HEM survey}

The AEM survey was carried out using the 6 frequency $(0.4$ to $110 \mathrm{kHz})$ RESOLVE HEM system (Fugro Airborne Surveys) as part of a research project into the application of AEM in the UK environment. The survey area covers a 1 x $1.5 \mathrm{~km}$ block taking in the target landfill and a regional fault to the north. Magnetic data were also acquired. Several issues relating to detailed towed-bird AEM data acquisition were revealed. Overflights above the local village (Fauldhouse) were not permitted so that flight lines just to the south of the target were curtailed by climbs and veers. Although a N-S line separation of $20 \mathrm{~m}$ was specified, only a $40 \mathrm{~m}$ separation could be achieved using a relatively inexperienced pilot.

A $600 \times 600 \mathrm{~m}$ area in the vicinity of the former quarry/landfill (red polygon) is shown in Figure 1 with the flight line sampling, surface trace of the fault, borehole locations (two pairs) and the centre position of 3 follow-up Vertical Electric Soundings (VES).

\section{The Eastfield Quarry Landfill}

The quarry indicated in Figure 1 worked a sandstone outcrop within the Lower Coal Measures to a depth of $31 \mathrm{~m}$. The quarry was located on former (early 19'th century) colliery shafts. Two of these are known and another is suspected. Landfill operations began in the 1950's when the site was leased for domestic refuse. Industrial waste disposal began in 1963 and the type industrial wastes included paints, solvents, oils, sludges and treated cyanide i.e. large volumes of liquid waste products. From 1972, the Deposit of Poisonous Waste Act allowed 


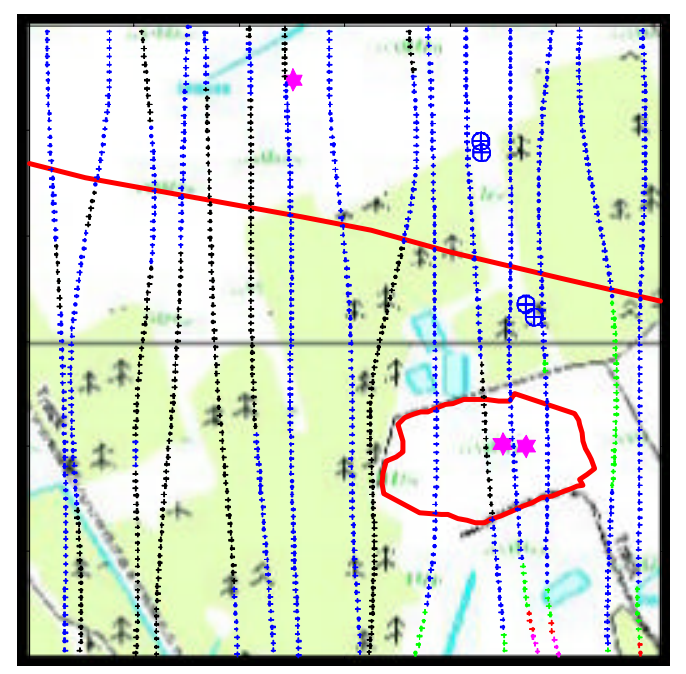

Figure 1. $600 \times 600 \mathrm{~m}$ area within the larger survey area showing quarry/landfill polygon (red), surface trace of fault (red line), recent boreholes (circled cross symbols) and centre locations of $3 \mathrm{VES}$ measurements (star symbols). Flight lines superimposed on background topographic map(@Crown copyright. All rights reserved).

for greater control and since that date, $47,000 \mathrm{~m}^{3}$ of liquid waste $\left(33,500 \mathrm{~m}^{3}\right.$ containing oils) were deposited. A permanent liquid waste lagoon formed, perched above one of the 19'th Century shafts. Input of solid waste ceased in 1979 and the landfill was covered and graded. The AEM survey took place some 24 years after closure.

Historically the active landfill was the subject of a detailed BGS hydrogeological characterization research programme (Harrison et al. 1981). Eleven boreholes were drilled; three of the boreholes were drilled into the landfill. At that time (1974), aqueous wastes were found to have migrated through the shafts and into shallow worked coal seams surrounding the site. Oils and acidic leachates were found in fractures within the underlying sandstone and also $300 \mathrm{~m}$ down dip (west) within the highest worked seam ( 46 mbgl).

A large area to the north of the landfill is due for regeneration in an ambitious scheme to develop the former colliery site. Initial phases of the scheme involve surface extraction of coal and fire clay. The environmental/technical issues of redevelopment have renewed interest in the extent of possible migration of source materials. One of the main issues of concern is the possibility of any leachate migration northwards from the landfill and the degree of any transgression across the fault.

\section{Results}

The magnetic survey data reveal two anomalies (Fig. 2). The main anomaly is a $1000 \mathrm{nT}$ dipolar perturbation associated with the landfill. This N-S oriented feature appears due to remnant magnetization within deposited ferrous materials. A further small anomaly (100 nT) appears in association with a long-term burn area across a coal spoil heap. The RESOLVE electromagnetic data comprise coupling ratios from 5 horizontal coplanar coil pairs (nominal frequencies of 400, 1500, 6400, 25000 and $11500 \mathrm{kHz}$ ) together with a coaxial pair operating at $3300 \mathrm{~Hz}$. Sampling of all data is at $10 \mathrm{~Hz}$ providing data every $3.2 \mathrm{~m}$ along flight lines.

These data can be used to provide a variety of half-space apparent conductivity maps together with approximate frequency-depth transform models. These procedures, while useful, do not provide sufficient resolution or discrimination to fully address the technical issues posed by the landfill. In order to fully exploit the information provided by any multi-frequency EM system it is necessary to undertake formal inversion of each 'sounding'. At present, routine procedures for airborne data are limited to 1D assessments. These models may then be stitched together to allow a consideration of the conductivity distribution within a subsurface volume. 


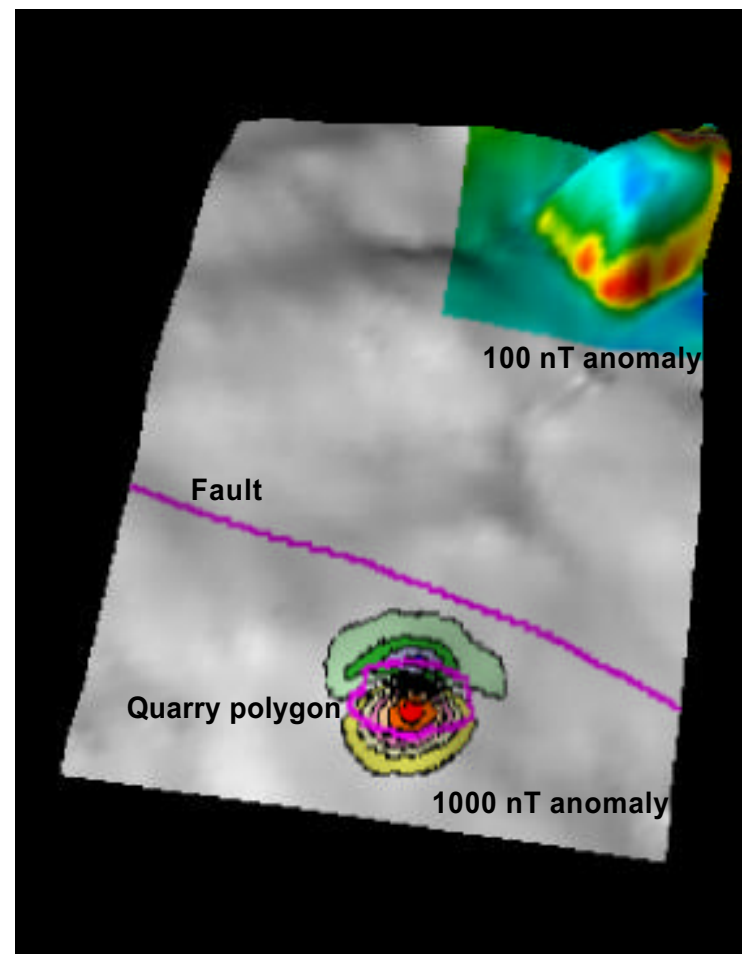

Figure 2. 1.4 x $1 \mathrm{~km}$ full survey area with TMI data contoured and anomaly in vicinity of spoil heap (NE corner) superimposed using different colour scale. Results draped on topography. Quarry/Landfill polygon and surface trace of fault are also shownl

Various forms of regularized (Occam) 1D inversion have been applied to the data. While limiting resolution in the vertical direction, such models are highly useful in mapping lateral changes within the subsurface volume. Using a realistic assignment of data errors and a 25 layer model (extending to a depth of $100 \mathrm{~m}$ ), chi-squared misfits around the expectation of 12 are achieved except on one central line through the landfill zone. The resulting conductivity models have been incorporated into a $3 \mathrm{D}$ visualization program that allows conductivity isosurfaces and isovolumes to be realized. Figure 3 shows a selected conductivity isovolume at $35 \mathrm{mS} / \mathrm{m}$ across the portion of the survey area shown in Figure 1.

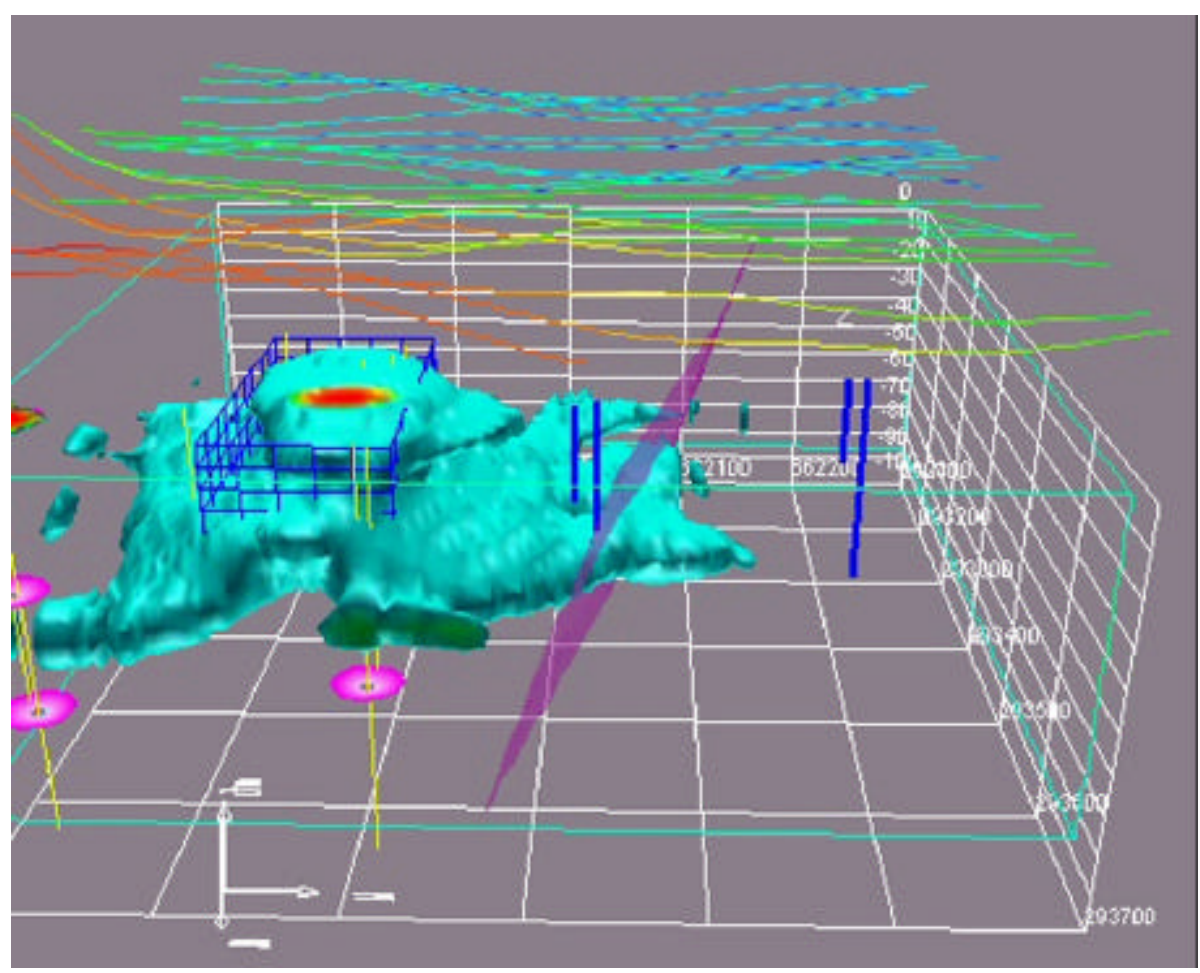

Figure 3. Conductivity isovolume ( $>35 \mathrm{mS} / \mathrm{m}$ ) across a $600 \times 600 \times 100 \mathrm{~m}$ volume, looking west. Uppermost lines are flight lines. Blue grid box indicates extent of former quarry. Dipping transparent plane represents Polkemmet fault. Vertical lines indicate investigation boreholes. 
Background conductivities (as measured by both airborne and ground data) of the Lower Coal Measure sequence are less than 10-15 mS/m. The fault, representing a down-throw of similar materials, has only a marginal conductivity expression. As indicated in Figure 3, the landfill zone contains a source zone of conductive materials $(>125 \mathrm{mS} / \mathrm{m})$. At conductivities $<125$ $\mathrm{mS} / \mathrm{m}$, the main breakout appears at the base of the landfill with a downward component of dip to the north. At intermediate levels, about a factor of 3 above background, the conductivity model provides evidence for a variety of lateral migration pathways, largely below the base of the quarry. A confined area of conductive breakout appears at a depth of about $8 \mathrm{~m}$ to the north of the landfill. The major northward breakout occurs at depths $>30 \mathrm{~m}$ and a conductive tongue traverses the fault largely below the base of recent investigation boreholes. To the west and south-west (not visible in Figure 2), deep breakout appears to correlate with the location/depth of the worked Upper Drumgray seam. This feature appears consistent with the interpretations derived from the borehole investigations noted previously.

While plausible, the degree to which the model can be considered valid without additional control information is debatable. Vertical conductivity models obtained from 2 VES soundings within the landfill confirm bulk conductivities of $\sim 100 \mathrm{mS} / \mathrm{m}$ at depths between 7.5 and $40 \mathrm{~m}$. Equivalence studies indicate that the base of the conductive zone is not well resolved, however.

\section{Conclusions}

This extremely small airborne HEM survey has highlighted a number of issues related to data acquisition at the site investigation scale. These include flight line density and interference from power lines (not discussed above). In order to extract pertinent information (in this landfill site context) from the 6 frequency data it was necessary to perform 1D inversion. Adequate misfits were achieved using regularized, Occam procedures. The resulting conductivity model appears to 'represent' a leaking landfill.

Due to the low conductivity of the Coal Measures, only the conductive component of leachate migration is resolved. The main potential pollutants are heavy metals, acids and organic matter (principally oils). Biological degradation within the mine workings is unlikely to be significant since conditions for efficient aerobic breakdown are lacking. Oils, perhaps accounting for only $10 \%$ of the liquid wastes, should remain resistive. The likely cause of the conductive component is likely to derive from the highly acidic and mobile sulphate component found in high concentrations (typically $>1000 \mathrm{mg} / \mathrm{l}$ ) found in the pore waters extracted by the borehole study. The precise geochemical nature of the conductive breakout remains speculative until further modern control information can be provided.

\section{Reference}

Harrison, I.B., Parker, A. and Williams, G.M., 1981. Investigation of the landfill at Eastfield Quarry, Fauldhouse, Westlothian, Scotland. Institute of Geological Sciences Report 81/13.

\section{Aknowledgement}

The assistance of Greg Paleolog and Mike Cain of Fugro Airborne Surveys is much appreciated. 